Bayly, N. J., C. Gómez, K. A. Hobson, and K. V. Rosenberg. 2016. Prioritizing tropical habitats for long-distance migratory songbirds: an assessment of habitat quality at a stopover site in Colombia. Avian Conservation and Ecology 11(2):5. http://dx.doi.org/10.5751/ACE-00873-110205 Copyright (C) 2016 by the author(s). Published here under license by the Resilience Alliance.

Research Paper

\title{
Prioritizing tropical habitats for long-distance migratory songbirds: an assessment of habitat quality at a stopover site in Colombia
}

\author{
Nicholas J. Bayly ${ }^{1}$, Camila Gómez ${ }^{1,2}$, Keith A. Hobson ${ }^{3,4}$ and Kenneth V. Rosenberg ${ }^{5}$ \\ ${ }^{1}$ SELVA: Investigación para la Conservación en el Neotropico, Bogotá, Colombia, ${ }^{2}$ Laboratorio de Biología Evolutiva de \\ Vertebrados, Universidad de Los Andes, Bogotá, Colombia, ${ }^{3}$ Environment Canada, Science and Technology Branch, ${ }^{4}$ Department \\ of Biology, University of Western Ontario, ${ }^{5}$ Cornell Lab of Ornithology, Ithaca, New York
}

\begin{abstract}
Long-distance migratory birds are declining globally and migration has been identified as the primary source of mortality in this group. Despite this, our lack of knowledge of habitat use and quality at stopovers, i.e., sites where the energy for migration is accumulated, remains a barrier to designing appropriate conservation measures, especially in tropical regions. There is therefore an urgent need to assess stopover habitat quality and concurrently identify efficient and cost-effective methods for doing so. Given that fuel deposition rates directly influence stopover duration, departure fuel load, and subsequent speed of migration, they are expected to provide a direct measure of habitat quality and have the advantage of being measurable through body-mass changes. Here, we examined seven potential indicators of quality, including body-mass change, for two ecologically distinct Neotropical migratory landbirds on stopover in shade-coffee plantations and tropical humid premontane forest during spring migration in Colombia: (1) rate of body-mass change; (2) foraging rate; (3) recapture rate; (4) density; (5) flock size; (6) age and sex ratios; and (7) body-mass distribution. We found higher rates of mass change in premontane forest than in shade-coffee in Tennessee Warbler Oreothlypis peregrina, a difference that was mirrored in higher densities and body masses in forest. In Gray-cheeked Thrush Catharus minimus, a lack of recaptures in shade-coffee and higher densities in forest, also suggested that forest provided superior fueling conditions. For a reliable assessment of habitat quality, we therefore recommend using a suite of indicators, taking into account each species' ecology and methodological considerations. Our results also imply that birds stopping over in lower quality habitats may spend a longer time migrating and require more stopovers, potentially leading to important carryover effects on reproductive fitness. Evaluating habitat quality is therefore imperative prior to defining the conservation value of newly identified stopover regions.
\end{abstract}

\section{Priorisation de milieux tropicaux visant des passereaux migrateurs de longue distance : évaluation de la qualité de l'habitat dans une halte migratoire en Colombie}

RÉSUMÉ. Les oiseaux migrateurs de longue distance sont en diminution sur la planète et la migration a été pointée du doigt comme source primaire de mortalité chez ce groupe. Malgré ce constat, notre manque de connaissance sur l'utilisation et la qualité de l'habitat aux haltes migratoires - c.-à-d. les sites où les oiseaux accumulent l'énergie en vue de la migration - limite notre capacité à déterminer les mesures de conservation appropriées, spécialement dans les régions tropicales. L'évaluation de la qualité de l'habitat aux haltes est donc urgente, de même que la détermination de méthodes efficaces et rentables pour s'y prendre. Étant donné que les taux d'accumulation d'énergie influent directement sur la durée de séjour aux haltes, la charge d'énergie au départ d'une halte et la vitesse subséquente de migration, on s'attend à ce qu'ils fournissent une mesure directe de la qualité de l'habitat; ils ont également l'avantage d'être mesurables au moyen de la variation de la masse corporelle. Dans la présente étude, nous avons examiné sept indicateurs potentiels de la qualité, dont la variation de la masse corporelle, pour deux oiseaux terrestres migrateurs néotropicaux distincts écologiquement, à des haltes situées dans des plantations de café poussant à l'ombre et une forêt tropicale humide de piémont au moment de la migration en Colombie : 1) taux de variation de la masse corporelle; 2) taux d'alimentation; 3) taux de recapture; 4) densité; 5) taille du groupe; 6) âge-ratio et sex-ratio; et 7) répartition de la masse corporelle. Nous avons obtenu des taux de variation de la masse corporelle plus élevés en forêt de piémont que dans les plantations de café pour la Paruline obscure Oreothlypis peregrina, une différence qui était corroborée par des densités et des masses corporelles plus élevées en forêt. Chez la Grive à joues grises Catharus minimus, une absence de recaptures dans les plantations de café et des densités plus élevées en forêt laissent aussi penser que la forêt fournit des conditions supérieures d'accumulation d'énergie. Afin d'obtenir une évaluation fiable de la qualité de l'habitat, nous recommandons d'utiliser une série d'indicateurs qui tiennent compte de l'écologie de chaque espèce et de considérations méthodologiques. Nos résultats indiquent aussi que les oiseaux qui s'arrêtent dans des milieux de moins bonne qualité pourraient passer plus de temps en migration et auraient besoin de plus nombreuses haltes, entraînant possiblement des effets rémanents sur leur valeur adaptative. Il est donc essentiel d'évaluer la qualité de l'habitat avant de déterminer la valeur de conservation de haltes nouvellement identifiées.

Key Words: density; fuel deposition rate; Gray-cheeked Thrush; habitat selection; Nearctic-Neotropical migratory birds; prioritization; shade coffee; Tennessee Warbler 


\section{INTRODUCTION}

Long-distance migratory birds travel vast distances every year, and their survival and reproductive success depend on the full array of habitats and sites occupied throughout the annual cycle (Sherry and Holmes 1996, Harrison et al. 2011). This dependence on multiple sites, often separated by thousands of kilometers, renders migratory birds especially vulnerable to widespread anthropogenic change (Newton 2004, Faaborg et al. 2010) and likely explains the persistent global declines documented in this group (Sanderson et al. 2006, Holmes 2007). Full life-cycle approaches to conserving migratory birds therefore require detailed knowledge of all aspects of the life cycle (Sheehy et al. 2010), yet, in the Americas, our lack of knowledge of stopover habitat, particularly in the tropics, is a major limiting factor for hemispheric initiatives aimed at reversing population declines (Faaborg et al. 2010).

During migration birds experience high mortality (Sillett and Holmes 2002, Newton 2006), and events on migration can also affect demography through carry-over effects on reproductive output (Baker et al. 2004, Finch et al. 2014). The success of migration typically depends on a series of stopover sites distributed between the breeding and stationary nonbreeding grounds, where the energy reserves for long-distance flights are acquired (Weber et al. 1998). Birds are therefore vulnerable to changes that alter the resource base at stopovers (Baker et al. 2004), especially if populations rely on a small number of sites to acquire energy, as recent stopover studies and new tracking technologies suggest (Bayly et al. 2013, McKinnon et al. 2013a). Identifying and prioritizing stopover regions and habitats is therefore a research and conservation priority (Faaborg et al. 2010).

The recent advent and deployment of light-archival geolocators has revolutionized the study of migration and is revealing previously unknown stopover regions at an unprecedented rate (McKinnon et al. 2013a). However, we still know little about the habitats used within these stopover areas or their relative quality, particularly in understudied regions like the Neotropics. The precision of geolocator data is often low (error > $100 \mathrm{~km}$; McKinnon et al. 2013b) and, as a result, numerous habitats may be present within newly identified stopover regions, as exemplified by studies in Colombia (Gómez et al. 2015). It is therefore essential to follow up studies that identify broad stopover regions with onthe-ground field studies, to accurately determine habitat use and quality within them.

Stopover sites and those used for premigratory fueling are an ideal system in which to study habitat quality because of the high energy requirements of migration, coupled with a selection pressure on birds to minimize the time spent migrating (Alerstam 2011). It follows that in habitats where birds make multiday stopovers, the rate of energy deposition is a direct reflection of quality, through its influence on stopover duration, departure fuel load, and the subsequent speed of migration (Weber et al. 1998, Dunn 2001, Bayly et al. 2012). Body mass changes in birds recaptured on multiple occasions are a good proxy for determining the rate and extent of energy deposition (Bayly et al. 2012); however, recapture rates at stopover sites are often low (Dunn 2001) and capture effects may give rise to spuriously negative rates (Schwilch and
Jenni 2001). Consequently it is important to test and compare alternative field methods that can provide efficient and cost effective surrogates for measuring body-mass change.

For Nearctic-Neotropical migratory birds that migrate between North and South America, the Sierra Nevada de Santa Marta in northern Colombia has recently been shown to be an important spring and fall stopover region (Bayly et al. 2012, 2013), particularly at midelevations (Gómez et al. 2015). At these elevations premontane forest has been extensively replaced by coffee plantations, as elsewhere in the Neotropics (Komar 2006, IDEAM 2010). Although shade-grown coffee can provide habitat for overwintering migratory birds (Tejeda-Cruz and Sutherland 2004, Komar 2006, Bakermans et al. 2012), its value as stopover and premigratory fueling habitat, when energetic requirements are elevated, is unknown. In this paper, we (1) assess the relative quality of shade coffee and premontane forest as stopover habitat for two species of Nearctic-Neotropical migratory birds on spring migration in the Sierra Nevada de Santa Marta; (2) compare and contrast the ability of seven different measures to distinguish the relative quality of shade coffee and premontane forest at a stopover site in Colombia (Table 1); and (3) discuss the possible impact stopover-habitat use may have on the subsequent migratory strategy of birds in this important region.

\section{METHODS}

\section{Study site}

This study took place in the Sierra Nevada de Santa Marta (hereafter SNSM), an isolated massif on Colombia's Caribbean coast (Fig. 1). We collected data in the Hacienda La Victoria $\left(11^{\circ}\right.$ $7^{\prime} 19.84^{\prime \prime} \mathrm{N}, 7^{\circ} 5^{\prime} 34.14^{\prime \prime} \mathrm{W}$ ), a shade coffee farm $19 \mathrm{~km}$ from the coast, where the main habitat types were humid tropical premontane forest $(\approx 300 \mathrm{ha})$ and shade coffee plantations $(\approx 300$ ha), both at an average elevation of $1200 \mathrm{~m}$ (Fig. 1). The forest consisted of old growth of unknown age and 20-30-year-old secondary growth. The canopy of the shade coffee was dominated by the leguminous "guamo" tree (Inga sp.; 84\% of trees), interspersed with "carboneros" (Albizia carbonaria; $1.6 \%$ ) and Trema micrantha (7\%). Canopy cover varied between $30 \%$ and $60 \%$.

\section{Study species}

The Gray-cheeked Thrush Catharus minimus is primarily an understory species that stops over in the SNSM for 12 to 14 days on spring migration, accumulating sufficient energy reserves to undertake a migratory flight of $>2500 \mathrm{~km}$ (Bayly et al. 2013). In contrast, the Tennessee Warbler Oreothlypis peregrina is a canopy dwelling warbler that both winters and stops over in the SNSM, with the wintering population undergoing premigratory fueling there prior to spring migration (Gómez et al. 2015). Both species breed in the boreal forests of North America and the migratory strategy they use to get there may be mediated by the habitats they select in the SNSM.

\section{Data collection}

We collected field data during four spring migration seasons to develop and compare seven measures of habitat quality for migratory birds, whose expected relationship with habitat quality 
Table 1. Seven potential measures of stopover habitat quality for long-distance migratory landbirds and their expected relationship with increasing habitat quality. The indicators that could be measured for our two study species are signaled in the final column (TEWA = Tennessee Warbler Oreothlypis peregrina; GCTH = Gray-cheeked Thrush Catharus minimus).

\begin{tabular}{|c|c|c|c|}
\hline Indicator & $\begin{array}{l}\text { Expected relation with increasing } \\
\text { habitat quality }\end{array}$ & Justification/References & Species tested \\
\hline Rate of body mass change & Positive & Dunn 2001, Bayly et al. 2012 & TEWA, GCTH \\
\hline Foraging rate $\mathrm{x}$ food type & Positive & $\begin{array}{l}\text { Lyons 2005, Rodewald and Brittingham } \\
2007\end{array}$ & TEWA \\
\hline Recapture rate & Positive & Implies that birds remain to fuel in habitat & TEWA, GCTH \\
\hline Species Density & Positive & Latta and Faaborg 2002, Buler et al. 2007 & TEWA, GCTH \\
\hline Flock size & Positive & See density & TEWA \\
\hline Age and sex ratios & More adults; more males & Marra and Holmes 2001 & TEWA, GCTH \\
\hline Body mass distribution & Mean and variation greater & Implies the ability to attain higher fuel loads & TEWA, GCTH \\
\hline
\end{tabular}

are described in Table 1. Because we recognize body-mass change as the most direct measure of energy deposition, and therefore of habitat quality, we focused our methods on obtaining adequate samples of recaptures for our target species through mist-netting. Constant effort mist-netting also allowed us to obtain data on recapture rates, age and sex ratios, and the distribution of body mass in the population. We used field observations in the vicinity of the mist-net stations to measure species density, flock size, and foraging rates of individual birds.

Fig. 1. Location of the study site in the Sierra Nevada de Santa Marta in northeastern Colombia and images of the two stopover habitats under study: A. Humid tropical premontane forest; B. Shade-coffee plantation.

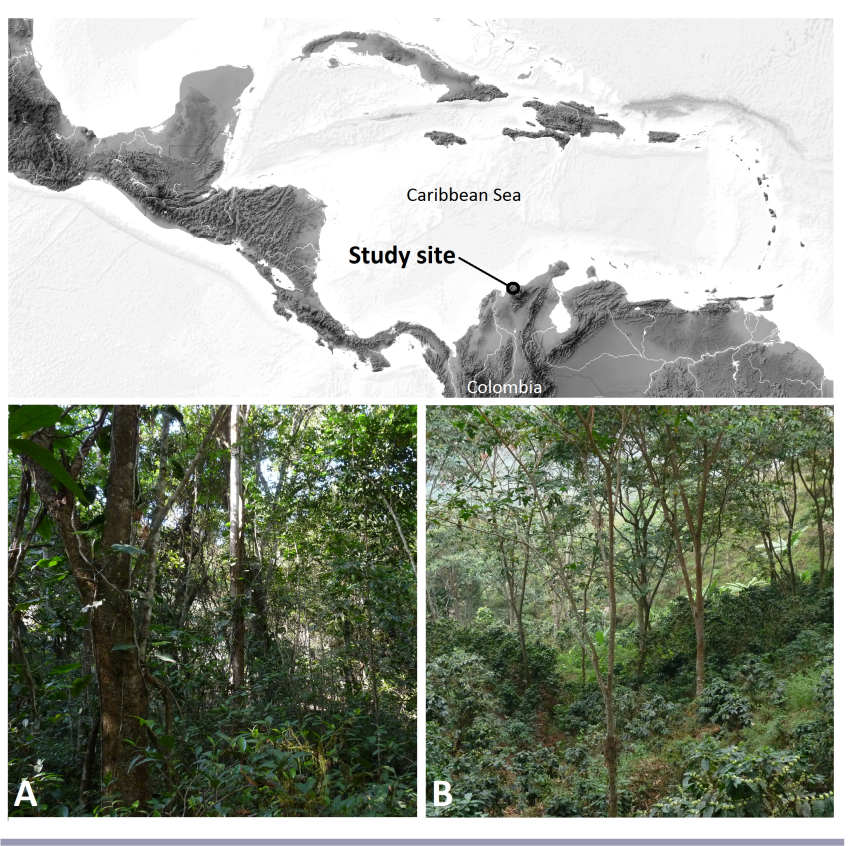

\section{Captures}

We operated two constant effort mist-net stations during the spring migration of 2010 and four stations (including those from 2010) per migration from 2011 to 2013. Stations were divided equally between forest and shade coffee and consisted of 6 to 10 mist-nets (12 or $18 \mathrm{~m}$ long, $32 \mathrm{~mm}$ and $36 \mathrm{~mm}$ mesh), with mistnets placed to maximize captures. Mean $( \pm S D)$ distance between stations was $0.72 \mathrm{~km}( \pm 0.28)$, range $0.3-1.05 \mathrm{~km}$. Mist nets were opened at dawn and operated for five hours per day and stations were operated either daily or on alternate days between 15 March and 10 May. Nets were checked every 30 to 40 minutes and captured birds were fitted with a uniquely numbered Porzanamade metal ring (reporting address: http://www.aselva.co). For all captures of Tennessee Warbler (TEWA from here on) and Gray-cheeked Thrush (GCTH) we recorded age and sex (TEWA only; [Pyle 1997]), fat score (Kaiser 1993), wing chord ( $\pm 1 \mathrm{~mm}$ ), and body mass ( $\pm 0.1 \mathrm{~g}$, using an electronic balance), prior to release (data available through http://data.sibcolombia.net/ conjuntos/resource/25).

\section{Observations}

To determine species density, we established six variable-distance transects along trails close to mist-net stations, each $500 \mathrm{~m}$ in length (aside one transect of $375 \mathrm{~m}$ ). Three transects were located in shade coffee (mean elevation $1225 \mathrm{~m}$, range $1125-1340 \mathrm{~m}$ ) and three in premontane forest (mean elevation $1385 \mathrm{~m}$, range 1300 $1450 \mathrm{~m}$ ). Transects were walked at a constant pace between 6:00 $\mathrm{AM}$ and 10:00 AM EST (mean duration \pm SD for $500 \mathrm{~m}$ transects $=20.3 \pm 4.0 \mathrm{~min}$ ), typically at intervals of three days, between 15 March and 10 May in three years (2010-2012). For all migratory birds detected, we estimated their perpendicular distance (nearest m) from the transect (Bibby et al. 1993).

Because TEWA often form mono-specific flocks, we documented flock sizes during 2012 and 2013 opportunistically while undertaking transects and mist-netting activities, recording the number of individuals, habitat (forest vs. shade coffee), date, and time of detection for each flock. Only flocks for which there was little doubt that all individuals had been detected were included in comparisons of flock size between habitats.

To quantify foraging behavior of TEWA at our site (GCTH were extremely difficult to follow), attack rates (rate of pecking behaviors with the bill) were recorded for randomly encountered individuals during 2012 and 2013 (Rodewald and Brittingham 2007). We only recorded one sequence per individual/encounter and varied recording locations to avoid sampling the same individual on more than one occasion (Hurlbert 1984). For each 
foraging sequence $(\mathrm{N}=42$ ) we recorded habitat, time of day, duration of sequence until a bird was lost/obscured from view (seconds), and the number of attacks on two different food types: insects and fruit. Here an "attack" was considered to be a foraging event. Wintering TEWA feed on insects, spiders, and fruits (often by piercing), as well as nectar (Curson et al. 1994).

\section{Data analysis and statistical procedures}

Because of data limitations and the differing behavior of TEWA and GCTH, not all of the seven measures of habitat quality listed below could be calculated for both species (see Table 1).

\section{Modeling body mass change}

For TEWA, we examined differences in rates of body mass change between habitats by modeling change in body mass in recaptured birds as a function of the number of days since first capture (Bayly et al. 2013). Change in body mass was expressed as a percentage of lean body mass (LBM, see below). Three birds that switched habitat were assumed to have spent more time in the habitat of recapture. Mass changes were modeled in the statistical software $\mathrm{R}$ using General Linear Models with normal errors ( $\mathrm{R}$ Development Core Team 2013). We used nine candidate models designed to test whether there was support for a difference in the rate of mass change between habitats (see Table 2 for models and variables). In all models we include the term Interval ( $\mathrm{I}=$ days between captures) to ensure that we were modeling the rate of change, and the term Time ( $\mathrm{T}=$ difference in hour of capture), to account for differences in the hour of capture between days. Model selection was based on Akaike Information Criteria with correction for small sample sizes (AICc) and models with $\Delta i<2$ were considered to be as plausible as the top model (Burnham and Anderson 2002). In order to create the dependent variablechange in body mass between captures expressed as a percentage of lean body mass - we first generated an estimate for LBM by regressing body mass against wing length for the subset of birds with fat score zero. LBM for a bird of mean wing length $(63 \mathrm{~mm})$, based on the resulting regression equation $(\mathrm{LBM}=2.763+$ $0.0808 *$ wing length), was $7.85 \mathrm{~g}$, which agrees with estimates from specimens after fat extraction, e.g., $7.94 \pm 0.13 \mathrm{~g}$ (Connell et al. 1960).

For GCTH we used models of body mass change presented previously for this species in our study area using the same methodology (Bayly et al. 2013). Here we present results only for premontane forest because no GCTH were recaptured in shade coffee.

\section{Foraging rates and diet}

Attack rates (number of pecks/min) in TEWA were not normally distributed and because they most closely reflect count data, we first compared AICc values between general linear models with normal errors (AICc 269.25, W $i=0.0$ ), Poisson errors (AICc 314.27, $\mathrm{W} i=0.0$ ), and a negative binomial error structure (AICc 244.71, $\mathrm{W} i=1.0$ ). The negative binomial model received overwhelming support, reflecting the Poisson-like distribution of the data but with a high degree of overdispersion, and was used to examine the effect of habitat, food type, date, and year on attack rate.

\section{Recapture rate}

Recapture rate was calculated as the percentage of individuals recaptured within the same year in each habitat, using data from
2010 and 2011 for GCTH and from 2011-2013 for TEWA. When two stations were run in each habitat, we calculated the mean recapture rate for the two stations. Effort in terms of days was very similar between stations but variation in the number of nets gave rise to differences in overall effort: however, because we would expect the number of recaptures to be proportional to the total number of captures in each station, we made no attempt to correct for effort. To test whether recapture rates by habitat were significantly different, we carried out a randomization test in $\mathrm{R}$ of the difference between the number of recaptures in each habitat (Difference $=$ No. recaps in forest - No. recaps in coffee) and compared the observed difference with the randomized distribution of differences (999 iterations).

Table 2. Model set to examine how habitat and other variables affected body mass change in recaptured Tennessee Warblers Oreothlypis peregrina at a spring stopover site in northern Colombia. The model containing habitat $(\mathrm{H})$ had the lowest AICc value and an Akaike weight (Wi) 62x greater than any other model. Parameter estimates and their $95 \%$ confidence intervals are given for the model containing habitat.

\begin{tabular}{|c|c|c|c|c|}
\hline $\begin{array}{l}\text { Model (Mass } \\
\text { change =) }\end{array}$ & Parameters & $\mathrm{AICc}$ & $\Delta \mathrm{AIC}$ & $\mathrm{Wi}$ \\
\hline $\mathrm{I}: \mathrm{H}+\mathrm{T}$ & 3 & 234.96 & 0.00 & 0.943 \\
\hline $\mathrm{I}: \mathrm{D}+\mathrm{T}$ & 2 & 242.98 & 8.02 & 0.017 \\
\hline $\mathrm{I}+\mathrm{T}$ & 2 & 243.21 & 8.25 & 0.015 \\
\hline $\mathrm{I}: \mathrm{M}+\mathrm{T}$ & 2 & 244.24 & 9.28 & 0.009 \\
\hline $\mathrm{I}+\mathrm{I}^{2}+\mathrm{T}$ & 3 & 244.90 & 9.94 & 0.007 \\
\hline $\mathrm{I}: \mathrm{A}+\mathrm{T}$ & 3 & 245.52 & 10.56 & 0.005 \\
\hline $\mathrm{I}: \mathrm{Y}+\mathrm{T}$ & 4 & 246.55 & 11.59 & 0.003 \\
\hline $\mathrm{I}+\mathrm{I}^{2}+\mathrm{I}^{3}+\mathrm{T}$ & 4 & 247.33 & 12.37 & 0.002 \\
\hline $\mathrm{I}: \mathrm{S}+\mathrm{T}$ & 4 & 247.63 & 12.67 & 0.002 \\
\hline Factor & Coefficient & SE & \multicolumn{2}{|c|}{$95 \% \mathrm{CI}$} \\
\hline Hour difference & 0.651 & 0.681 & \multicolumn{2}{|c|}{$-0.684-1.986$} \\
\hline Forest & 2.400 & 0.426 & \multicolumn{2}{|c|}{$1.565-3.235$} \\
\hline Coffee & 0.446 & 0.387 & \multicolumn{2}{|c|}{$-0.313-1.205$} \\
\hline
\end{tabular}

\section{Density estimation}

We estimated density using observations from variable-distance transects walked between 15 March and 20 April in 2011 and 2012 for TEWA and between 10 April and 10 May in 2010 and 2011 for GCTH, thereby capturing the main migration period of each species (Gómez et al. 2015). Taking into account the number of detections/year, years were combined for GCTH but not for TEWA. Individuals recorded $>25 \mathrm{~m}$ from the transect center were excluded and because TEWA is a flocking species, detections were analyzed in clusters for this species. To minimize any observer bias, we analyzed records from just two observers. To account for any differences in detectability, datasets for each habitat were analyzed separately with the software Distance 6.0 (Thomas et al. 2010) using the conventional distance sampling engine and poststratifying by year. Grouping of distance bands was carried out following visual inspection of the detection function histograms. We estimated a global detection function and evaluated its fit for half-normal, hazard-rate and negative 
Fig. 2. A. Fuel deposition rates in Tennessee Warblers Oreothlypis peregrina (TEWA) were faster in premontane forest than in shade coffee plantations, as reflected by body mass changes in individual birds (symbols) recaptured at a spring stopover site in northern Colombia. B. Gray-cheeked Thrushes Catharus minimus (GCTH) were able to greatly increase their body mass (energy reserves) in premontane forest (Figure adapted from Bayly et al. 2013). Body mass change is expressed as a percentage of lean body mass (LBM) and plotted against the number of days since first capture. The predicted change in mass (lines) from a Generalized Linear Model is shown separately for shade-coffee (dashed line) and premontane forest (solid lines).

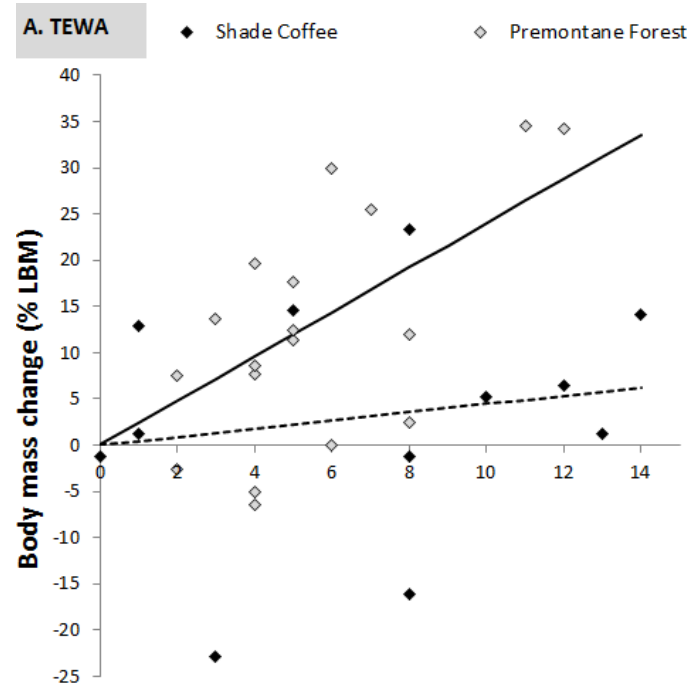

Days elapsed since first capture

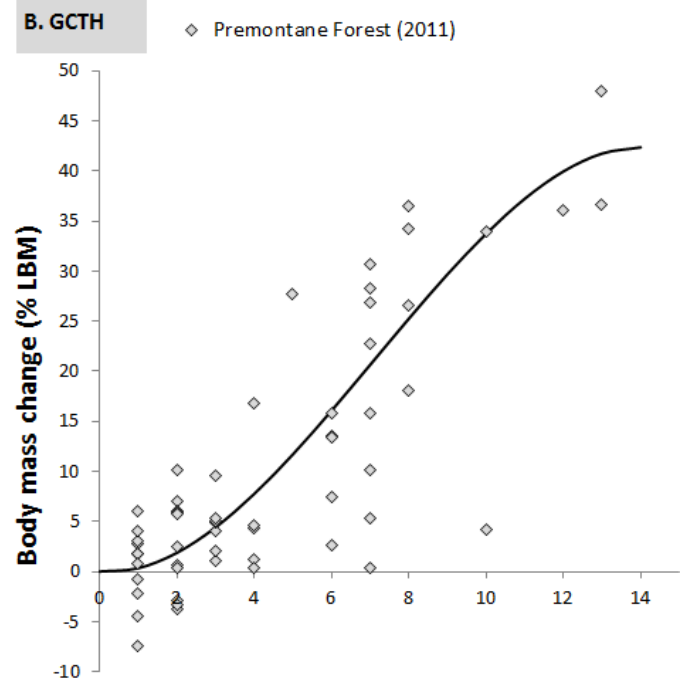

Days elapsed since first capture exponential models with cosine, simple-polynomial and hermitepolynomial series expansions (Hedley and Buckland 2004). The best-fitting model based on AIC was used to estimate density by stratum (year).

\section{Flock size}

Flock size in TEWA was not normally distributed, so we compared flock sizes between habitats using a Mann-Whitney test (two-tailed test, significance level 0.05).

\section{Age and sex ratios}

To determine whether age or sex ratios differed between habitats, Chi-squared tests were performed on the total number of immature and adult birds captured in each habitat and separately for the total number of male and female birds (sex was only determined for TEWA). We analyzed totals for each year separately as well as combining years (2011-2013). Expected values were calculated by multiplying the total number of captures in forest by the corresponding fraction for each age and sex in shade coffee and vice-versa.

\section{Body mass distribution}

We divided the range of recorded body masses from captured birds into categories, each covering a $1 \mathrm{~g}$ interval in TEWA (range $7.4-13.5 \mathrm{~g}$ ) and a $2 \mathrm{~g}$ interval in GCTH (range $24.2-45.6 \mathrm{~g}$ ). Analyzing years separately, we calculated the number of individuals in each body mass category for each habitat, for a range of dates on which forest and shade coffee stations were run simultaneously. The resulting category totals for each habitat were compared using a chi-squared analysis, with expected values for forest being estimated from the corresponding fraction in the shade coffee and vice-versa. We combined body masses across stations within in each habitat, such that distributions reflected the extent of variation within each habitat, nonetheless, mean body mass for individual stations was consistently higher in forest relative to shade coffee.

\section{RESULTS}

\section{Models of body mass change}

For TEWA, a model in which body mass increased as a linear function of the number of days since first capture and in which the rate of change was a function of habitat, received 62 times more support than a model without habitat (Table 2; Recaptures in coffee $\mathrm{N}=12$, in forest $\mathrm{N}=17$ ). Average rates of mass gain were estimated to be five times higher in forest $(2.4 \% \mathrm{LBM} /$ day $)$ compared to shade coffee ( $0.5 \%$ LBM/day; Table 2 ; Fig. $2 \mathrm{~A})$. No GCTH were recaptured in shade coffee, but birds recaptured in premontane forest increased their body mass by $2.6 \%$ and $3.5 \%$ LBM/day in 2010 and 2011, respectively, based on Bayly et al. 2013 (Fig. 2B).

\section{Foraging rate and diet}

We recorded 42 foraging sequences in TEWA totaling 33 minutes and 19 seconds, 18 directed toward fruit (forest only) and 24 toward insects (both habitats). When comparing models including the factors habitat, food type, year, date, and duration of foraging sequence, a model containing food type best explained variation in attack rates $\left(\mathrm{AICc}=242.48, w_{i}=0.44\right)$. This model reflects the 
finding that birds made multiple attacks in quick succession on a given fruit or clump of fruit, while attacks against insects were less frequent (Fig. 3). A model nesting food type within habitat received marginal support $\left(\mathrm{AIC}=244.71, w_{i}=0.14\right)$, suggesting that foraging rates for insects varied little between habitats. The lack of observations of fruit consumption in shade coffee is evidence for differences in diet between habitats.

Fig. 3. Comparison of foraging rates (attacks/minute) of Tennessee Warblers Oreothlypis peregrina in forest (light gray) and shade coffee plantations (dark gray) differentiating between food items (fruit vs. insects) at a spring stopover site in northern Colombia. No individuals were recorded feeding on fruit in the shade coffee plantations. Rectangles represent the interquartile range, the dividing line is the median, while whiskers represent maximum or minimum values. Superimposed on the boxplots are the data points.

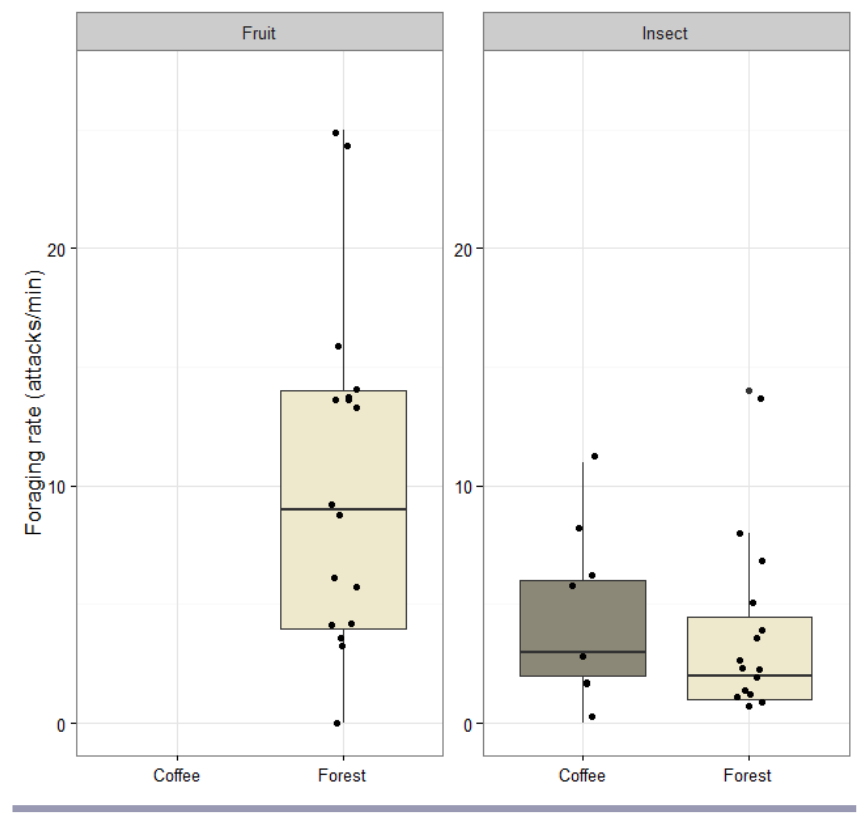

\section{Recapture rate}

Recapture rates in TEWA were low, less than $6 \%$ in all habitats/ years, and were marginally higher in forest in two years and in shade coffee in one year. Averaging across years, rates were extremely similar between habitats (Coffee 3.2\% from 317 captures; Forest $2.5 \%$ from 690 captures), and this was supported by a nonsignificant difference with a randomized distribution of values $(\mathrm{P}=0.332$, Fig. A1.1). In GCTH, recapture rate was zero in shade coffee in both years ( 0 recaptures from 96 captures), while in premontane forest it varied between 14\% in 2010 (229 captures) and $11 \%$ in 2011 (326 captures). A randomization test confirmed that rates in GCTH were significantly different between habitats $(\mathrm{P}<0.001$, Fig. A1.1).

\section{Density estimates}

For all estimates the half-normal detection function with cosine expansion received most support from AIC and was used to estimate densities. Mean density in premontane forest was up to 4.8 times higher than in shade coffee for TEWA and 2.9 times higher for GCTH (Fig. 4). This difference was consistent between years in TEWA, but because of the limited number of detections in individual years, for GCTH we had to combine years to generate a robust estimate. In TEWA, estimates for individual transects varied considerably, both in forest and coffee, suggesting that densities were not uniform, perhaps due to flocking behavior.

Fig. 4. The density (individuals $/ \mathrm{km}^{2} \pm \mathrm{SE}$ ) of Tennessee Warblers Oreothlypis peregrina and Gray-cheeked Thrushes Catharus minimus was higher in premontane forest (grey symbols) than in shade-coffee plantations (black symbols) at a spring stopover site in northern Colombia. Estimates were corrected for detectability using the software DISTANCE.

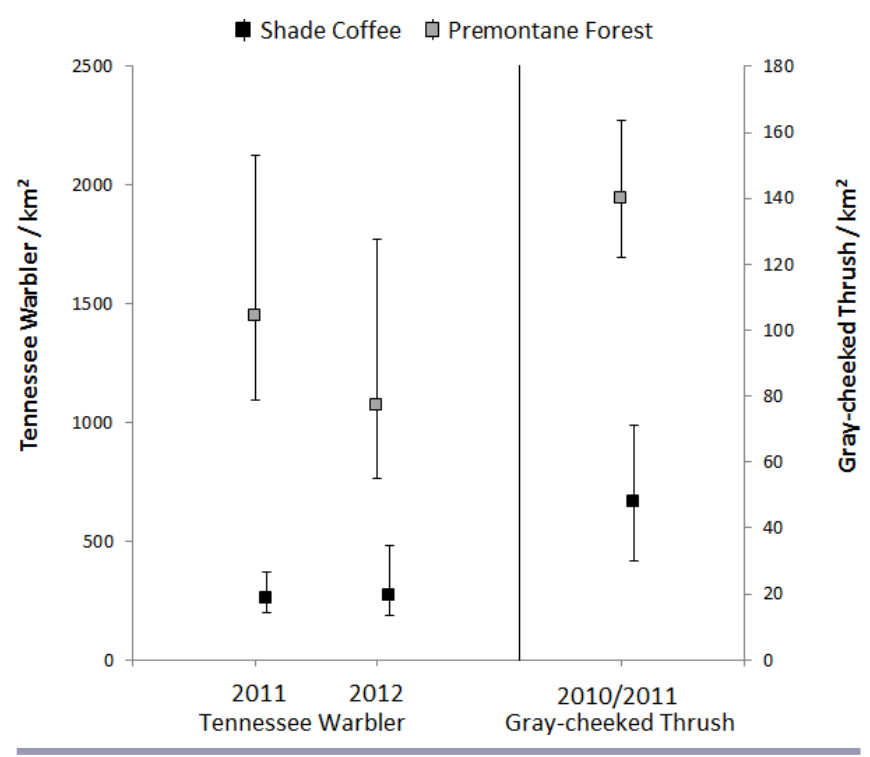

\section{Flock size}

The size of TEWA flocks in forest was significantly greater than those recorded in shade coffee (Mann-Whitney Test, $\mathrm{U}=2.5, \mathrm{Z}$ $=3.88, \mathrm{df}=22, p<0.001)$. Flocks in shade coffee were small and varied little in size (Mean $\pm \mathrm{SE}=3.1 \pm 0.28$ birds, range 2 to 4 , $\mathrm{N}=11$ ), while there was considerable variation in forest, with some flocks numbering $>100$ individuals (Mean $\pm \mathrm{SE}=44.3$ \pm 14.5 birds, range 4 to $175, \mathrm{~N}=12$; Fig. A1.2).

\section{Age and sex ratios}

Age and sex ratios in captured TEWA, regardless of habitat, differed from a 1:1 ratio, with immature birds being more common than adults (3:1) and males being more abundant than females (1.6:1). Age ratios did not differ significantly between habitats when analyzing years separately ( $p>0.7$ in all three years), but there was a weak difference when combining years, with fewer adults than expected occurring in forest $\left(x^{2}=3.72\right.$, $\mathrm{df}=1, p=$ 0.05 ). Sex ratios differed between habitats when combining years, with more males than expected occurring in forest $\left(x^{2}=4.24\right.$, df $=1, p=0.04$ ), although biologically the difference was small (forest $63 \%$ males vs. coffee $59 \%$ males). When analyzing years separately, more males occurred in forest in 2012 (57\% vs. 47\%; $\left.x^{2}=5.18, \mathrm{df}=1, p=0.02\right)$ and in $2013\left(67 \%\right.$ vs. $61 \% ; x^{2}=6.24$, $\mathrm{df}=1, p=0.01)$ but not in $2011\left(62 \%\right.$ vs. $64 \% ; x^{2}=0.58, \mathrm{df}=1$, $p=0.44)$. Age ratios in GCTH did not differ between habitats (Coffee $71 \%$ adults; Forest $69 \%$ adults; $x^{2}=0.7$, df $=3, p=0.87$ ). 


\section{Body mass distribution}

An initial examination of mean body mass among mist-netting stations, found a consistent pattern of higher body mass in forest versus coffee, but also variation between stations within the same habitat in certain years. When combining stations within habitats, we found consistent differences in the body mass distribution of TEWA captured in forest versus shade coffee in three separate years $\left(2011, x^{2}=615.4, \mathrm{df}=5, p<0.001 ; 2012, x^{2}=45.0\right.$, df $=4$, $\left.p<0.001 ; 2013, x^{2}=373.0, \mathrm{df}=5, p<0.001\right)$. The majority of birds captured in shade coffee had low body masses ( $85 \%$ of birds $<10 \mathrm{~g}$ ), giving rise to a strong positive skew in distribution (Fig. 5). In contrast, body mass was more normally distributed in the forest (Fig. 4) and $40 \%$ of birds were captured with a body mass $>10 \mathrm{~g}$. In GCTH, a greater proportion of heavier birds also occurred in premontane forest $\left(2010, x^{2}=31.5\right.$, $\mathrm{df}=6, p<0.001$; 2011, $\left.x^{2}=282.0, \mathrm{df}=6, p<0.001\right)$.

Fig. 5. Both (A) Tennessee Warblers Oreothlypis peregrina and (B) Gray-cheeked Thrushes Catharus minimus carried larger energy reserves on first capture in premontane forest than in shade coffee at a spring stopover site in northern Colombia, as inferred through differences in the distribution of body mass. The percentage of birds in each body mass class is the average of three consecutive years (2011-2013) for Tennessee Warblers and two years (2011 and 2012) for Gray-cheeked Thrush.
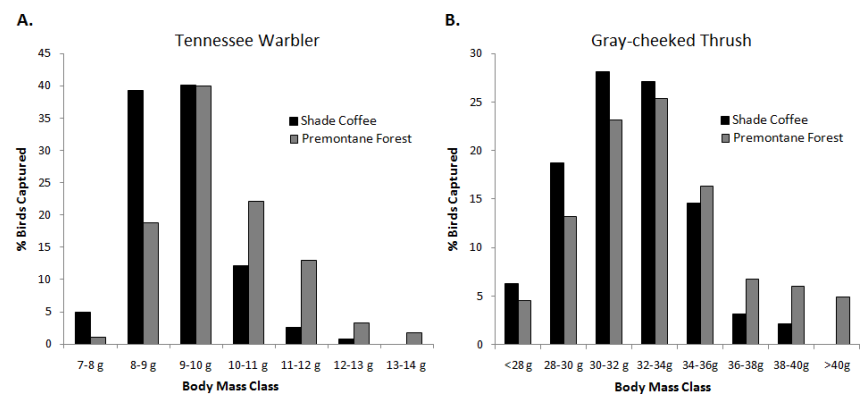

\section{DISCUSSION}

We consider the rate of energy deposition, measured through changes in body mass, to be the most unambiguous indicator of stopover habitat quality. Indeed, if the primary function of stopovers is energy deposition for a subsequent flight stage, then resource levels and their influence on fuel deposition should be the main determinant of habitat quality (Dunn 2001, Bayly et al. 2012). For recaptured Tennessee Warblers we recorded large increases in body mass in premontane forest, but not in shade coffee. In Gray-cheeked Thrush mass gains of up to $40 \%$ of lean body mass were recorded in forest but the lack of recaptures in shade coffee meant it was not possible to calculate mass gain in that habitat. Nonetheless, the lack of recaptures combined with the near absence of birds with body masses $>36 \mathrm{~g}$ in shade coffee (Fig. 5), suggest that Gray-cheeked Thrush rarely refuel in this habitat.

These findings, combined with higher densities and significantly greater body mass in individuals of both species in forest, provide, for the first time, an insight into the relative quality of these two tropical habitats for birds on stopover. Indeed, it is striking that despite markedly higher densities in premontane forest, Tennessee
Warbler still gained mass there at faster rates than in shade coffee, implying that density dependence effects on habitat quality are not strong for this species. The generality of these results across northern Colombia and elsewhere in the Neotropics, and for other species, must be investigated with more extensive surveys and intensive local field studies, taking into account the variety of management practices employed in shade coffee plantations.

Our study also attempted to overcome the methodological challenges associated with determining habitat quality for migratory birds in Neotropical regions. In particular, we sought to identify easier-to-obtain surrogates for rates of mass change because obtaining sufficient recaptures to assess the latter can be very labor intensive. The difference in quality between habitats at our study site, as indicated by direct measures of refueling rates, was also reflected in density estimates and in the distribution of body mass of both species, suggesting that these two measures may serve as reliable indicators of quality. Recapture rates, foraging rates and flock size also showed potential to act as measures of quality, but their utility is expected to be directly related to a given species' ecology. Meanwhile, age and sex ratios did not differ between habitats in our study species and may not serve as indicators of quality during stopover, in contrast to findings for over-wintering American Redstart Setophaga ruticilla in Jamaica (Johnson et al. 2006). Given the correlated nature of several of the measures considered here, we recommend evaluating a suite of indicators that are relevant to each species' ecology and basing conclusions on their overall patterns (Johnson 2007).

\section{Indicators of habitat quality}

In this study, it was possible to compare and contrast rates of body mass change between shade coffee and premontane forest for Tennessee Warblers but not for Gray-cheeked Thrushes. In Gray-cheeked Thrushes, the absence of recaptures in shade coffee made a direct comparison of fueling rates impossible, a potentially common scenario where habitats do not support appropriate fueling conditions. Only by combining the results from more than one indicator can we interpret this lack of recaptures as a signal of low habitat quality for Gray-cheeked Thrush, e.g., when considered in the light of large mass gains in forest, the lack of recaptures in shade coffee supports the conclusion that forest provided superior fueling conditions. In addition, while rates of mass change in Tennessee Warbler were on average five times faster in forest, three individuals recaptured in coffee gained mass at rates similar to birds in forest. It is therefore possible that birds exhibiting negative or slow rates were overwintering individuals, recaptured prior to the initiation of premigratory fueling (Neto et al. 2008). Indeed, between-year recaptures suggest that a small fraction of Tennessee Warblers at the study site were overwinter residents (of 746 birds captured in 2011 and 2012, 14 [1.8\%] were recaptured in subsequent years). This example highlights the potential difficulties of interpreting data from sites used for both stopover and for premigratory fueling by an overwintering population. However, when we consider this alongside the marked differences in density between habitats, it becomes clear that forest, at the population level, allows vastly more Tennessee Warblers to fuel per unit area.

As with changes in body mass, foraging rates may allow for a direct assessment of food availability at stopover sites (Lyons 2005, Rodewald and Brittingham 2007). For Tennessee Warblers, 
attack rates on insects were similar between habitats, implying little difference in insect abundance. However, there was a marked difference in diet between habitats, because birds were only observed consuming fruits in forest. The clumped and abundant nature of fruit resources allowed for rapid successive pecking behaviors, giving rise to high attack rates and presumably intake rates. Fruits are known to have a higher fat and carbohydrate content relative to insects, promoting faster fueling rates (Bairlein 1998), and may explain the faster rates of mass change in Tennessee Warblers in forest. Observations of Gray-cheeked Thrush feeding on fruits in premontane forest (Bayly et al. 2013), and the absence of appropriate fruiting trees in shade coffee, may also explain why this species did not appear to stopover in coffee. These findings highlight the critical importance of taking diet into account and the potential for diet selection to serve as an additional proxy for habitat quality, when the nutrient value of food items is known (Bairlein 1998, Smith et al. 2007). Nonetheless, foraging rates alone may not be a suitable indicator for all species, especially those like the Gray-cheeked Thrush that are difficult to follow visually.

Recapture rates from constant effort mist-net stations are potentially an excellent indicator of whether migratory birds remain in a habitat to refuel or not. For Gray-cheeked Thrush, an understory species that flies at the height of a typical mist-net, the lack of recaptures in shade coffee would appear to be a clear signal of nonuse for multiday stopovers. In contrast, for a canopy dwelling species like the Tennessee Warbler, which rarely flies at the height of standard mist-nets, recapture rates are unlikely to be a reliable indicator of use/quality because rates may depend more on habitat structure than use (Remsen and Good 1996). How factors such as habitat structure, foraging ecology, and stopover duration affect recapture rates should therefore be carefully considered before drawing conclusions.

Given that migratory birds are expected to seek out habitats supporting the highest rates of fuel deposition, density has been considered to be a reliable indicator of stopover habitat quality under a wide range of conditions because birds making multiday stopovers respond numerically to resource availability (Buler et al. 2007, Buler and Moore 2011). However, density can also be misleading if there are associated density-dependence effects on habitat quality, such as diminished resources or active exclusion by dominant individuals (Van Horne 1983). In our study, we found markedly higher densities of both species in forest relative to shade coffee, and this finding was corroborated by higher fueling rates and body masses. Density estimates, considered in combination with other factors, may therefore be one of the most cost-effective and efficient means of assessing habitat quality. This does not preclude, however, the initial establishment of evidence for multiday stopovers (Delmore et al. 2012) and active energy deposition (Bayly et al. 2013), because high densities can occur at sites rarely used for fueling, e.g., sites used in emergencies, often referred to as "fire escapes" (Mehlman et al. 2005). Our finding that densities were not uniform but varied between transects, presumably because of flocking behavior or clumped resources, e.g., fruiting trees, emphasizes the importance of surveying a representative area of the habitats of interest (Thomas et al. 2010).

Like density estimates, flock size has the potential to elucidate differences between habitats. Indeed, if flock sizes can be combined with a measure of encounter rate, they may outperform traditional density estimates for flocking species, in which clumping breaks several of the underlying assumptions of distance estimation (Thomas et al. 2010). Flocking behavior may also inform us about other ecological processes; indeed, the predominance of large Tennessee Warbler flocks in forest may be a response to the clumped nature of food resources, e.g., fruit, and the associated increase in predation risk when birds concentrate in a small area.

Unlike the indicators discussed above, age and sex ratios did not follow a clear pattern at our study site. Dominant adult birds and males occupy the best wintering habitats in some migratory birds (Lopez and Greenberg 1990, Johnson et al. 2006), but we only found weak evidence for a greater proportion of male Tennessee Warblers in forest vs. shade coffee. The flocking behavior of Tennessee Warblers or the limited time during which birds on stopover might establish territories or dominance mediated distributions, probably best explains why these indicators did not perform well here. It is also possible that the apparent lack of a strong density-dependent effect on fuelling rates, is evidence for a reduced role of food limitation and hence competition in shaping the observed patterns.

The distribution of body mass in captured birds differed between habitats, paralleling our results for body-mass change and density. Birds captured in shade coffee had lower masses on average and fewer individuals were captured at high body masses relative to forest, a difference that may arise if birds regularly abandon the shade coffee for the forest. The lack of recaptures of Gray-cheeked Thrushes in coffee supports this hypothesis, as do confirmed movements of marked Tennessee Warblers from shade coffee to forest: including two birds that moved $>1 \mathrm{~km}$ within three hours of initial capture. The distribution of body mass in a stopover population is not only shaped by birds that remain to fuel but also by transient birds passing through. Indeed, there are sites where birds carrying large fuel reserves make emergency stops when flying conditions are unfavorable (Bayly and Rumsey 2010); again, this highlights the need to first establish whether birds actually fuel in a region to avoid arriving at the wrong conclusion.

Past studies have attempted to examine habitat quality through two alternative proxies for energy deposition rates: (A) a regression analysis of body mass against time of capture (Dunn 2001); and (B) plasma-metabolite levels (Acevedo Seaman et al. 2006). We have not included these measures here because the former suffers methodological issues and may not provide reliable estimates of mass change under a variety of conditions (Bayly et al. 2012, Minias and Kaczmarek 2013), while the latter is costly and may not reflect fueling performance over periods of days (Smith and McWilliams 2010). Importantly, neither of these approaches discriminates between mass changes in birds undertaking multiday stopovers versus transients.

The results presented here highlight the fact that no one indicator can be reliably used to assess habitat quality in stopover regions, and like previous studies of habitat quality (Johnson 2007), we recommend using a combination of measures tailored to our knowledge of the focal species' ecology. Given the urgent need to identify and prioritize the stopover regions and habitats used by long-distance migrants (Mehlman et al. 2005, Faaborg et al. 2010), observational studies combining density estimation with foraging observations could rapidly provide us with vital baseline 
Avian Conservation and Ecology 11(2): 5

http://www.ace-eco.org/vol11/iss2/art5/

information. That said it must first be established that focal species are undergoing multiday stopovers because these measures will not serve their purpose at sites where (transient) migrants only stop to rest between nocturnal flights.

\section{Habitat quality and migration strategy}

The differences we found between forest and shade coffee at our study site, based on multiple lines of evidence, have major implications for how stopover strategies in migratory birds may be affected by habitat availability and choice. The contrasting rates of fuel deposition in Tennessee Warblers, for example, suggest that birds fueling in shade coffee must either stay longer than those in forest or depart the study site with less energy. Either way, this implies that the temporal (time spent at stopovers) and/ or the spatial (number and location of stopover sites) organization of migration can vary with stopover habitat, with likely fitness costs mediated through carry-over effects (Norris et al. 2004, Harrison et al. 2011). It was previously shown that Gray-cheeked Thrush stopping over for 12-14 days in the SNSM accumulate sufficient energy reserves to undertake a migratory flight $>2500$ $\mathrm{km}$, allowing them to overfly the Caribbean Sea to the southern United States (Bayly et al. 2013). We found no evidence that shade coffee allows for the same strategy at our study sites and therefore reduced availability of tropical forests could have population-level implications for this and other Nearctic-Neotropical migratory birds during stopover.

The clear conservation implications of these results highlight the need to conduct on-the-ground field studies to assess habitat quality at stopover sites in the Neotropics before defining conservation priorities within a region. For example, although shade coffee has been widely acknowledged as a good habitat for overwintering migratory birds (Tejeda-Cruz and Sutherland 2004, Bakermans et al. 2012), there is no unequivocal demonstration that it is of similar or higher quality than the forested habitats it replaces (Komar 2006). Our results from a stopover site in Colombia suggest that shade coffee may provide inferior conditions, relative to natural forest, for birds on migration, especially if key habitat components such as fruiting trees and shrubs are not retained. Nonetheless, it is important to note that shade-coffee supported positive fuelling rates in Tennessee Warblers and is likely preferable to alternative agricultural systems such as sun coffee or cattle pastures. We therefore recommend that further studies be conducted to assess the relative quality of shade coffee and other agroforestry systems compared with native forests. These should take into account canopy composition, local environmental conditions, and management practices to determine whether our results represent a widespread pattern and to identify best practices to improve quality in agroforestry systems, such as the planting or retention of fruiting trees. We have shown that such an assessment can be achieved in a cost-effective manner by evaluating a suite of measures, obtained through a combination of constant-effort mist-netting and field observations. Applying this methodology across potential stopover regions throughout northern South and Central America will be an essential step toward the development of full life-cycle conservation strategies for Nearctic-Neotropical migratory birds.
Responses to this article can be read online at: http://www.ace-eco.org/issues/responses.php/873

\section{Acknowledgments:}

We thank Mickey and Claudia Weber for providing unequivocal support for our work in Hacienda La Victoria, and our research assistants, Laura Cárdenas, Valentina Gómez, Hernán Arias, and Jeyson Sanabria, for their devotion to collecting high quality data. Esteban Botero helped improve an earlier version of this manuscript. This research was financed by the Rufford Small Grants Foundation, Environment Canada, and the Cornell Lab of Ornithology. Preparation of the manuscript was carried out without financial assistance. Corpamag and the ANLA issued the research permits for this project. We thank two anonymous reviewers whose constructive comments improved this manuscript.

\section{LITERATURE CITED}

Acevedo Seaman, D. A, C. G. Guglielmo, R. W. Elner, and T. D. Williams. 2006. Landscape-scale physiology: site differences in refueling rates indicated by plasma metabolite analysis in freeliving migratory sandpipers. Auk 123:563-574. http://dx.doi. org/10.1642/0004-8038(2006)123[563:LPSDIR]2.0.CO;2

Alerstam, T. 2011. Optimal bird migration revisited. Journal of Ornithology 152:5-23. http://dx.doi.org/10.1007/s10336-011-0694-1

Bairlein, F. 1998. The effect of diet composition on migratory fuelling in Garden Warblers Sylvia borin. Journal of Avian Biology 29:546-551. http://dx.doi.org/10.2307/3677174

Baker, A. J., P. M. González, T. Piersma, L. J. Niles, I. D. L. S. do Nascimento, P. W. Atkinson, N. A. Clark, C. D. T. Minton, M. K. Peck, and G. Aarts. 2004. Rapid population decline in Red Knots: fitness consequences of decreased refuelling rates and late arrival in Delaware Bay. Proceedings of the Royal Society London B 271:875-882. http://dx.doi.org/10.1098/rspb.2003.2663

Bakermans, M. H., A. D. Rodewald, A. C. Vitz, and C. Rengifo. 2012. Migratory bird use of shade coffee: the role of structural and floristic features. Agroforestry Systems 85:85-94. http://dx. doi.org/10.1007/s10457-011-9389-0

Bayly, N. J., C. Gómez, and K. A. Hobson. 2013. Energy reserves stored by migrating Gray-cheeked Thrushes Catharus minimus at a spring stopover site in northern Colombia are sufficient for a long-distance flight to North America. Ibis 155:271-283. http:// dx.doi.org/10.1111/ibi.12029

Bayly, N. J., C. Gómez, K. A. Hobson, A. M. González, and K. V Rosenberg. 2012. Fall migration of the Veery (Catharus fuscescens) in northern Colombia: determining the energetic importance of a stopover site. Auk 129:449-459. http://dx.doi. org/10.1525/auk.2012.11188

Bayly, N. J., and S. Rumsey. 2010. Garden Warbler Sylvia borin migration in sub-Saharan West Africa. Bird Study 25:59-61.

Bibby, C. J., N. Burgess, and D. Hill. 1993. Bird census techniques. Third edition. Cambridge University Press, London, UK. 
Buler, J. J. and F. R. Moore. 2011. Migrant-habitat relationships during stopover along an ecological barrier: extrinsic constraints and conservation implications. Journal of Ornithology 152 (Suppl1):101-112. http://dx.doi.org/10.1007/s10336-010-0640-7

Buler, J. J., F. R. Moore, and S. Woltmann. 2007. A multi-scale examination of stopover habitat use by birds. Ecology 88:1789-1802. http://dx.doi.org/10.1890/06-1871.1

Burnham, K. P., and D. R. Anderson. 2002. Model selection and multinomial inference: a practical information-theoretic approach. Springer, New York, New York, USA.

Connell, C. E., E. P. Odum, and H. Kale. 1960. Fat-free weights of birds. Auk 77:1-9. http://dx.doi.org/10.2307/4082380

Curson, J., D. Quinn, and D. Beadle. 1994. New World warblers. Christopher Helm, London, UK.

Delmore, K. E., J. W. Fox, and D. E. Irwin. 2012. Dramatic intraspecific differences in migratory routes, stopover sites and wintering areas, revealed using light-level geolocators. Proceedings of the Royal Society London B 279:4582-4589. http:// dx.doi.org/10.1098/rspb.2012.1229

Dunn, E. H. 2001. Mass change during migration stopover: a comparison of species groups and sites. Journal of Field Ornithology 72:419-432. http://dx.doi.org/10.1648/0273-8570-72.3.419

Faaborg, J., R. T. Holmes, A. D. Anders, K. L. Bildstein, K. M. Dugger, S. A. Gauthreaux, P. Heglund, K. A. Hobson, A. E. Jahn, D. H. Johnson, S. C. Latta, et al. 2010. Conserving migratory land birds in the New World: Do we know enough? Ecological Applications 20:398-418. http://dx.doi.org/10.1890/09-0397.1

Finch, T., J. Pearce-Higgins, D. I. Leech, and K. Evans. 2014. Carry-over effects from passage regions are more important than breeding climate in determining the breeding phenology and performance of three avian migrants of conservation concern. Biodiversity and Conservation 23:2427-2444. http://dx.doi. org/10.1007/s10531-014-0731-5

Gómez, C., V. Gómez-Bahamón, L. Cárdenas-Ortíz, and N. J. Bayly. 2015. Distribution of Nearctic-Neotropical migratory birds along a South American elevation gradient during spring migration. Wilson Journal of Ornithology 127:72-86. http://dx. doi.org/10.1676/14-017.1

Harrison, X. A., J. D. Blount, R. Inger, D. R. Norris, and S. Bearhop. 2011. Carry-over effects as drivers of fitness differences in animals. Journal of Animal Ecology 80:4-18. http://dx.doi. org/10.1111/j.1365-2656.2010.01740.x

Hedley, S. L., and S. T. Buckland. 2004. Spatial models for line transect sampling. Journal of Agricultural, Biological, and Environmental Statistics 9:181-199. http://dx.doi. org/10.1198/1085711043578

Holmes, R. T. 2007. Understanding population change in migratory songbirds: long-term and experimental studies of Neotropical migrants in breeding and wintering areas. Ibis 149:2-13. http://dx.doi.org/10.1111/j.1474-919x.2007.00685.x

Hurlbert, S. H. 1984. Pseudoreplication and the design of ecological field experiments. Ecological Monographs 54:187-211. http://dx.doi.org/10.2307/1942661
IDEAM. 2010. Leyenda Nacional de Coberturas de la Tierra. Metodología CORINE Land Cover adaptada para Colombia Escala 1:100.000. Instituto de Hidrología, Meteorología y Estudios Ambientales. Bogotá, Colombia.

Johnson, M. D. 2007. Measuring habitat quality: a review. Condor 109:489-504. http://dx.doi.org/10.1650/8347.1

Johnson, M. D., T. W. Sherry, R. T. Holmes, and P. P. Marra. 2006. Assessing habitat quality for a migratory songbird wintering in natural and agricultural habitats. Conservation Biology 20:1433-1444. http://dx.doi.org/10.1111/j.1523-1739.2006.00490 $\mathrm{x}$

Kaiser, A. 1993. A new multi-category classification of subcutaneous fat deposits of songbirds. Journal of Field Ornithology 64:246-255.

Komar, O. 2006. Ecology and conservation of birds in coffee plantations: a critical review. Bird Conservation International 16:1-23. http://dx.doi.org/10.1017/S0959270906000074

Latta, S. C., and J. Faaborg. 2002. Demographic and population responses of Cape May Warblers wintering in multiple habitats. Ecology 83:2502-2515. http://dx.doi.org/10.1890/0012-9658(2002) 083[2502:DAPROC]2.0.CO;2

Lopez, A., and R. Greenberg. 1990. Sexual segregation by habitat in migratory warblers in Quintana Roo, Mexico. Auk 107:539-543.

Lyons, J. E. 2005. Habitat-specific foraging of Prothonotary Warblers: deducing habitat quality. Condor 107:41-49. http://dx. doi.org/10.1650/7462

Marra, P. P., and R. T. Holmes. 2001. Consequences of dominance-mediated habitat segregation in American Redstarts during the nonbreeding season. Auk 118:92-104. http://dx.doi. org/10.1642/0004-8038(2001)118[0092:CODMHS]2.0.CO;2

McKinnon, E. A., K. C. Fraser, and B. J. M. Stutchbury. $2013 a$. New discoveries in landbird migration using geolocators, and a flight plan for the future. Auk 130:211-222. http://dx.doi. org/10.1525/auk.2013.12226

McKinnon, E. A., C. Q. Stanley, K. C. Fraser, M. MacPherson, G. Casbourn, P. P. Marra, C. E. Studds, N. Diggs, and B. J. Stutchbury. 2013b. Estimating geolocator accuracy for a migratory songbird using live ground-truthing in tropical forest. Animal Migration 1:31-38.

Mehlman, D. W., S. E. Mabey, D. N. Ewert, C. Duncan, B. Abel, D. Cimprich, R. D. Sutter, and M. Woodrey. 2005. Conserving stopover sites for forest-dwelling migratory landbirds. Auk 122:1281-1290. http://dx.doi.org/10.1642/0004-8038(2005)122[1281: CSSFFM]2.0.CO;2

Minias, P., and K. Kaczmarek. 2013. Population-wide body mass increment at stopover sites is an unreliable indicator of refuelling rates in migrating waders. Ibis 155:102-112. http://dx.doi. org/10.1111/ibi.12014

Neto, J. M., V. Encarnação, P. Fearon, and A. G. Gosler. 2008. Autumn migration of Savi's Warblers Locustella luscinioides in Portugal: differences in timing, fuel deposition rate and non-stop flight range between the age classes. Bird Study 55:78-85. http:// dx.doi.org/10.1080/00063650809461507 
Newton, I. 2004. Population limitation in migrants. Ibis 146:197-226. http://dx.doi.org/10.1111/j.1474-919X.2004.00293. $\mathrm{x}$

Newton, I. 2006. Can conditions experienced during migration limit the population levels of birds? Journal of Ornithology 147:146-166. http://dx.doi.org/10.1007/s10336-006-0058-4

Norris, D. R., P. P. Marra, T. K. Kyser, T. W. Sherry, and L. M. Ratcliffe. 2004. Tropical winter habitat limits reproductive success on the temperate breeding grounds in a migratory bird. Proceedings of the Royal Society London B 271:59-64. http://dx. doi.org/10.1098/rspb.2003.2569

Pyle, P. 1997. Identification guide to North American birds, Part II: Columbidae to Ploceidae. Slate Creek, Bolinas, California, USA.

$\mathrm{R}$ Development Core Team. 2013. $R$ : A Language and Environment for Statistical computing. The R Project for Statistical Computing, Vienna, Austria.

Remsen, J. V., Jr., and D. A. Good. 1996. Misuse of data from mist-net captures to assess relative abundance in bird populations. Auk 113:381-398. http://dx.doi.org/10.2307/4088905

Rodewald, P. G., and M. C. Brittingham. 2007. Stopover habitat use by spring migrant landbirds: the roles of habitat structure, leaf development, and food availability. Auk 124:1063-1074. http://dx.doi.org/10.1642/0004-8038(2007)124[1063:SHUBSM]2.0. $\mathrm{CO} ; 2$

Sanderson, F. J., P. F. Donald, D. J. Pain, I. J. Burfield, and F. P. J. van Bommel. 2006. Long-term population declines in AfroPalearctic migrant birds. Biological Conservation 131:93-105. http://dx.doi.org/10.1016/j.biocon.2006.02.008

Schwilch, R., and L. Jenni. 2001. Low initial refueling rate at stopover sites: a methodological effect? Auk 118:698-708. http:// dx.doi.org/10.1642/0004-8038(2001)118[0698:LIRRAS]2.0.CO;2

Sheehy, J., C. M. Taylor, K. S. McCann, and D. R. Norris. 2010. Optimal conservation planning for migratory animals: integrating demographic information across seasons. Conservation Letters 3:192-202. http://dx.doi.org/10.1111/j.1755-263X.2010.00100. $\mathrm{x}$

Sherry, T. W., and R. T. Holmes. 1996. Winter habitat quality, population limitation and conservation of Neotropical-Nearctic migrant birds. Ecology 77:36-48. http://dx.doi.org/10.2307/2265652

Sillett, T. S., and R. T. Holmes. 2002. Variation in survivorship of a migratory songbird throughout its annual cycle. Journal of Animal Ecology 71:296-308. http://dx.doi.org/10.1046/

j.1365-2656.2002.00599.x

Smith, S. B., K. H. McPherson, J. M. Backer, B. J. Pierce, D. W. Podlesak, and S. R. McWilliams. 2007. Fruit quality and consumption by songbirds during autumn migration. Wilson Journal of Ornithology 119:419-428. http://dx.doi.org/10.1676/06-073.1
Smith, S. B., and S. R. McWilliams. 2010. Patterns of fuel use and storage in migrating passerines in relation to fruit resources at autumn stopover sites. Auk 127:108-118. http://dx.doi. org/10.1525/auk.2009.09139

Tejeda-Cruz, C., and W. J. Sutherland. 2004. Bird responses to shade coffee production. Animal Conservation 7:169-179. http:// dx.doi.org/10.1017/S1367943004001258

Thomas, L., S. T. Buckland, E. A. Rexstad, J. L. Laake, S. Strindberg, S. L. Hedley, J. R. Bishop, T. A. Marques, and K. P. Burnham. 2010. Distance software: design and analysis of distance sampling surveys for estimating population size. Journal of Applied Ecology 47:5-14. http://dx.doi.org/10.1111/ j.1365-2664.2009.01737.x

Van Horne, B. 1983. Density as misleading indicator of habitat quality. Journal of Wildlife Management 47:893-901. http://dx. doi.org/10.2307/3808148

Weber, T. P., B. J. Ens, and A. I. Houston. 1998. Optimal avian migration: a dynamic model of fuel stores and site use. Evolutionary Ecology 12:377-401. http://dx.doi.org/10.1023/ A: 1006560420310
Editor-in-Chief: Ryan Norris
Sponsored by the Society of Canadian Ornithologists and Bird Studies Canada Parrainée par la Société des ornithologistes du Canada et Etudes d'oiseaux Canada 


\section{APPENDIX A}

Table A1.1. Model set to examine how habitat and other variables affected attack rates in Tennessee Warblers at a spring stopover site in northern Colombia.

\begin{tabular}{llcccc}
\hline Model (Attack rate $=$ ) & Error structure & DF & AICc & $\Delta$ AIC & Wi \\
Substrate & Neg. Binomial & 3 & 242.48 & 0.32 & 0.44 \\
Site + Substrate & Neg. Binomial & 4 & 244.71 & 2.55 & 0.14 \\
Site:Substrate & Neg. Binomial & 4 & 244.71 & 2.55 & 0.14 \\
Year & Neg. Binomial & 3 & 246.46 & 4.30 & 0.06 \\
Site & Neg. Binomial & 3 & 251.25 & 9.09 & 0.01 \\
Duration & Neg. Binomial & 3 & 252.75 & 10.59 & 0.00 \\
Date & Neg. Binomial & 3 & 252.80 & 10.64 & 0.00 \\
\hline
\end{tabular}


Figure A1.1. To determine if recapture rates were significantly different we carried out a randomization test of the difference in number of recaptures by habitat (999 iterations). A. TEWA showed no significant difference in the number of recaptures in coffee and forest as shown by the randomized distribution versus the observed value (red vertical line, $\mathrm{P}=0.332$ ). B. GCTH did show a significantly higher recapture rate in forest relative to coffee $(\mathrm{P}<0.001)$ when compared to the randomized distribution.

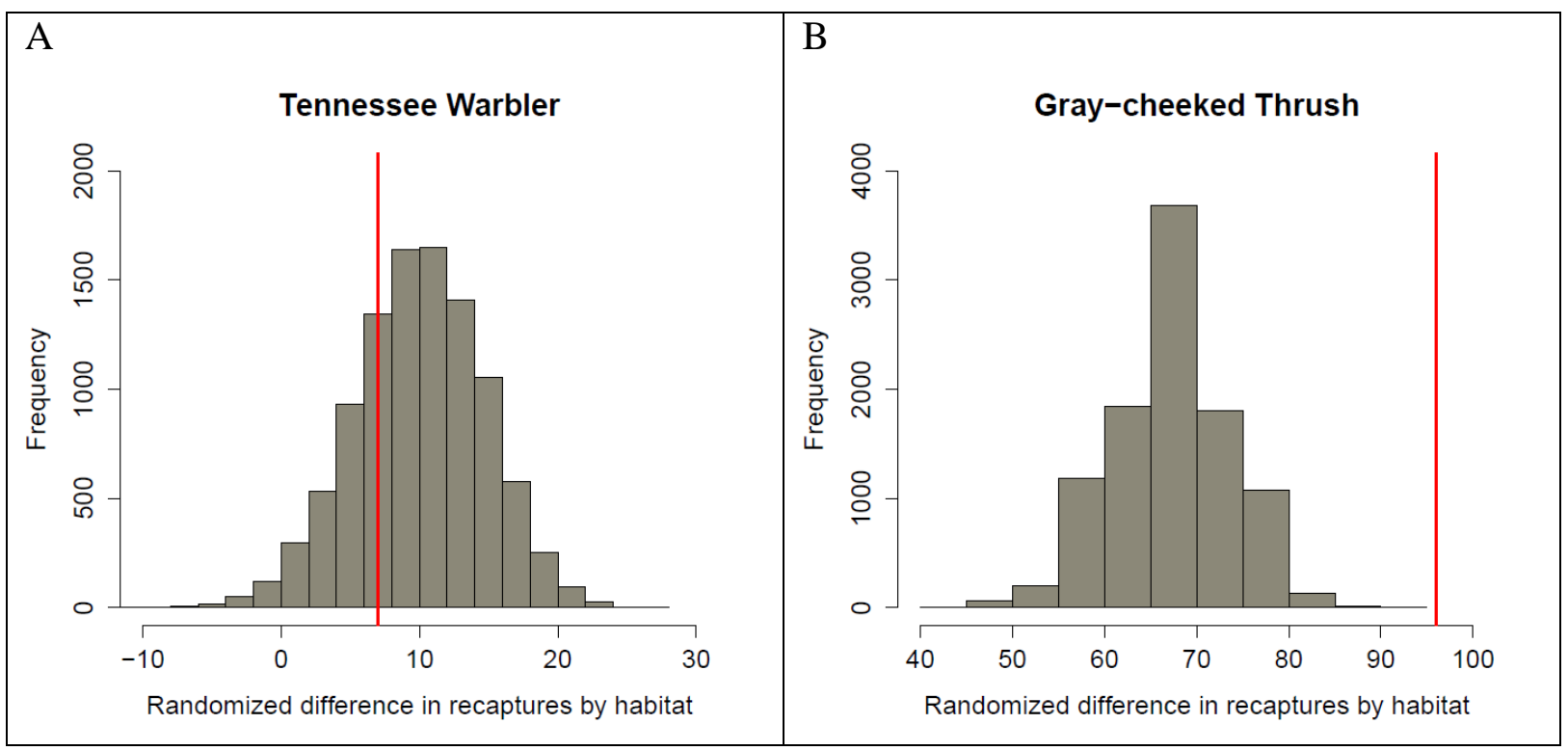


Figure A1.2. Boxplot comparing Tennessee Warbler flock sizes in forest and shade coffee plantations at a spring stopover site in northern Colombia. Rectangles represent the interquartile range, the dividing line is the median, while whiskers represent maximum or minimum values. Superimposed on the boxplots are the data points.

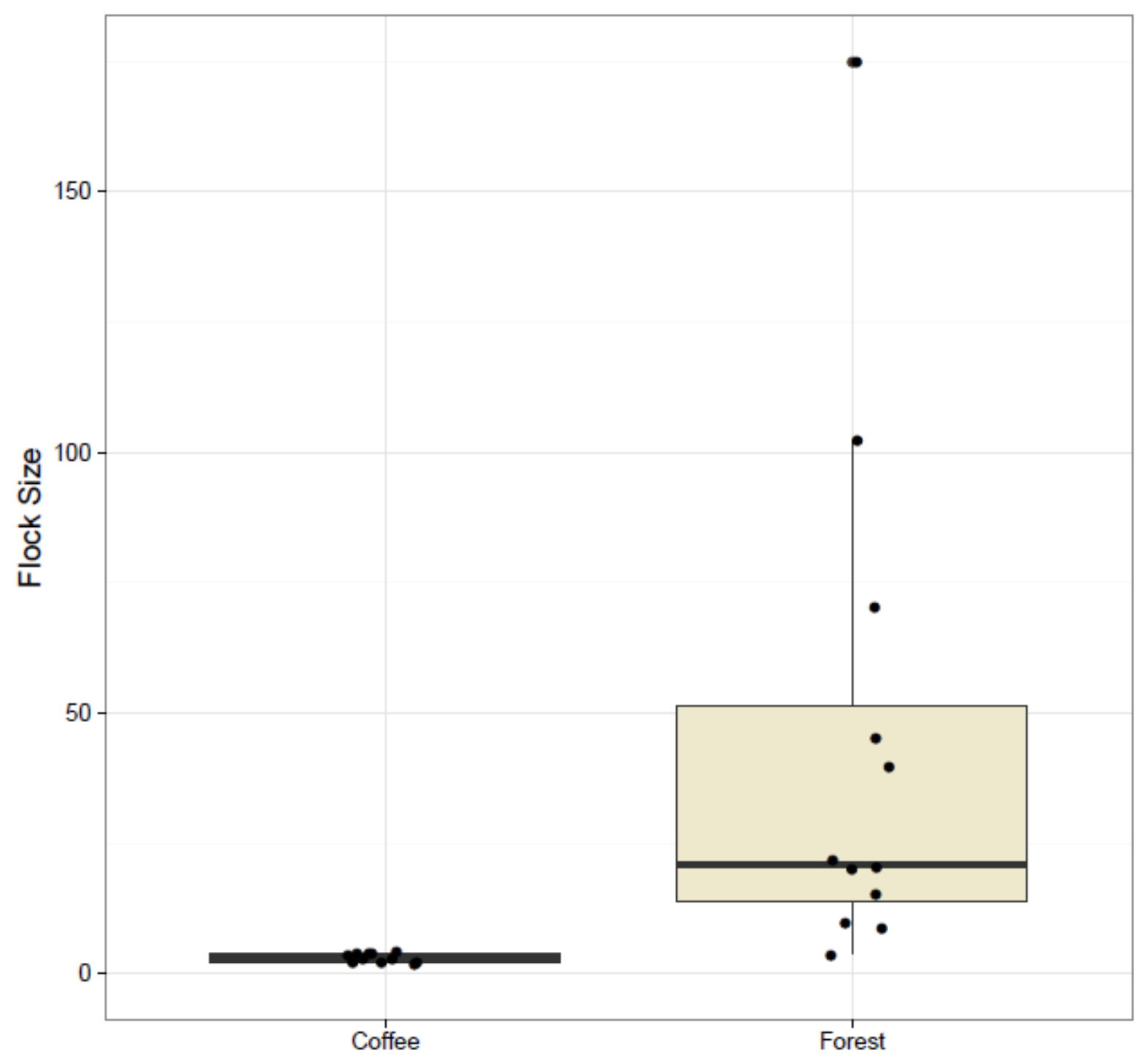

